\title{
Attitudes and Performance of Workers Preparing for the Fourth Industrial Revolution
}

\author{
SangWoo Hahm ${ }^{1}$ \\ College of Business Administration, Soongsil University, \\ Seoul, 06978 - Korea. \\ [e-mail: bload@ssu.ac.kr] \\ *Corresponding author: SangWoo Hahm
}

Received February 26, 2018; revised July 11, 2018; accepted July 19, 2018; published August 31, 2018

\begin{abstract}
Recently, the most frequently studied topics related to the fourth industrial revolution (FIR) are Big data, AI, Cloud Computing and Internet of Things- these four components are collectively known as the main components of the FIR (henceforth MCs). The MCs have a wide range of effects on workers' performance. As such it is imperative that these components are properly understood. This understanding will lead to a proper recognition of the attitudes that workers need to adopt to the MCs. Specifically, the attitudes of workers to several variables need to be examined, including importance, intention to use, belief in improvement, efficacy to use, and negative cognition. Each of these variables plays a role in determining how worker's performance in the FIR era will change. The performance-related variables such as self-efficacy, expectations, and acceptance of change are also crucial. These variables are related to creation of new opportunities, and can greatly influence performance in the FIR era. This study explains how specific attitudes to MCs improve performance-related factors for FIR. The adoption of these attitudes will ultimately lead to more successful adaption to the FIR era.
\end{abstract}

Keywords: The fourth industrial revolution, performance, attitude

A preliminary version of this paper was presented at ICONI 2017, and was selected as an outstanding paper. 


\section{Introduction}

The fourth industrial revolution (FIR) is characterized by a fusion of technologies blurring the lines between the physical, digital, and biological spheres [1]. The FIR is already underway and it is expected to have a critical and diverse influence on both individual lives and on society as whole [2]. The FIR has the potential to improve the quality of lives and raise global income levels [1,3]. The world needs to accept that the FIR is coming, prepare for the challenges that it will bring and and fully utilize the many new opportunities that it will present. Recently, the most commonly studied topics related to the FIR are Big data, Artificial Intelligence (AI), Cloud Computing, and internet of things (IoT) [1, 4, 5]. Big data, AI, Cloud Computing, and IoT (hereafter these components are called the MCs: the Main Factos in the FIR) will have diverse effects on the future of human life and workers in organizations. This study has three main aims. Firstly, it will explain the characteristics and expected impact of MCs, such as increasing performance and creating new values. Secondly, it will investigate workers' specific attitudes to MCs which are connected to workers' performance: 1) importance, which is the degree that workers think something is important; 2) intention to use, which is the intention to put something to use by workers; 3) belief in improvement, which is whether or not workers believe that something will help them to improve work results; 4) efficacy to use, which is workers thinking that they have the ability to make good use of something; and 5) negative cognition, which is the awareness/belief held by workers that they will be affected negatively by something. Thus, depending on the specific attitudes to MCs that they have, workers' performance may be different in the FIR era. Thirdly, this research investigates workers' psychological states as related to changes which may be brought by the FIR. This is done by examining the role of efficacy, expectancy and acceptance of change. These factors are related to the preparation and the creation of new opportunities for the future, and hence the performance of the FIR era. This study explains the relevance to individuals of how specific attitudes to MCs increase efficacy, expectancy, and acceptance of change. Moreover, it will suggest certain attitudes that workers should adopt in order to prepare for the FIR. These attitudes will improve efficacy, expectancy and acceptance of change. People who have these attitudes will be more adaptable and likely to achieve higher performance in the FIR era.

\section{Literature Review}

\subsection{Attitudes to MCs}

MCs have already begun to have a significant impact in areas such as the work environment and organizational performance, and this influence will increase greatly in the immediate future. As such, the core attitudes that people have to these factors are important, and will help to determine the nature and extent of the influence of the MCs on individuals worklives.. There are five crucial attitudes to MCs. First, workers may have an attitude that regards MCs as important. Importance is the degree to which workers think that MCs are important to their lives. If people think a particular object is important, they will try to utilize it and they will be interested in the changes it brings and its development. This attitude will improve performance. For instance, workers with an attitude that Big data is important will try to learn as much as they can about this technology. This is turn will lead to them getting better results with Big data. Second, intention to use is concerned with a workers' intention to use MCs more often. Intention to use means that workers either already have the ability to make 
good use of a particular factor or that they will learn how to utilize it. For example, workers who intend to use Cloud Computing are generally more competent with computing, and wish to know more about it, then workers without this intention, which allows them to better exploit it and in turn achieve better results. A high degree of intention to use will have a positive relationship with high performance in the FIR era. Third, belief in improvement means simply that workers believe that MCs will help them to improve overall work performance. Workers who believe that MCs will be beneficial to performance will already have experience improving their performance through MCs, or will be working to actively use MCs. For example, workers who believe that IoT is related to performance will more actively use it. Therefore, having a positive beliefs in MCs will be related to performance improvement. Fourth, efficacy to use is relates to the extent that workers think they have the ability to make effective use of MCs. If workers have the ability and confidence to use a particular technology, the chances of achieving higher performance through these technologies increases. Thus it is to be expected that an employee with a sense of efficacy about utilizing Big data will produce better results through this technology in the FIR era. Fifth, negative cognition refers to aworkers belief or awareness that MCs will negatively affect their lives. Positive as well as negative attitudes can affect performance. If workers see MCs as having a negative impact, they will not use them. In the FIR era, performance will be hampered if good use is not made of MCs. For example, workers who do not think Cloud Computing is useful will not use this technology, and it can be expected that their overall performance will be lower than the workers using cloud computing.

\subsection{Performance-related variables to prepare for FIR}

Self-efficacy, expectancy, and acceptance of change influence worker's levels of motivation, and the degree of success an organization has at making changes. When workers have positive attitudes to these factors, their performance will improve, and organizations have a much higher chance of being able to find a new business model that fits the FIR era.

\subsubsection{Self-efficacy}

Self-efficacy refers to people's belief in their capabilities to produce a specified level of performance. These beliefs create diverse effects on cognitive, emotional, motivational, and selection processes [6]. Thus, self-efficacy influences the behavior and performance of workers [7]. Workers who have higher self-efficacy are more likely to accept new challenges. Further, an efficacious outlook promotes creativity and a deeper commitment to work. In turn, these factors can increase workers' efforts to overcome failure or frustration. Thus selfefficacy brings higher levels of performance, and reduces negative factors such as stress and depression $[6,8]$. Self-efficacy is a belief that performance can be achieved in a given situation, and it improves motivation [9]. Therefore, workers who have a high sense of efficacy in the FIR era will be able to adapt more easily and achieve better and more consistent results. This study works with an operational definition of self-efficacy for FIR as a worker's belief that they will be able to carry out their work well in the FIR era. Selfefficacy will play a critical role in preparing for the era of the FIR.

\subsubsection{Expectancy}

Expectancy is a belief about a future state of affairs, involving subjective estimates of the likelihood of future events ranging from the merely possible to virtually certain [10]. 
Expectancy involves effort-performance relationship and performance-reward relationship [11], and outcome expectancy [12]. Positive expectancy related to performance in the future will stimulate current motivation. Humans can not predict the future perfectly. Thus, people choose to believe in alternatives based on potential outcomes for the future. In this case, their behavior is influenced by not only the preference for the outcome, but also the expectation that there will be certain outcomes [12, 13]. Hence, when thinking about the future, such as the era of the FIR , people will have specific expectations. and these expectations may affect current levels of motivation. Expectancy has a direct impact on current behavior and performance. Further, positive expectancy for specific jobs can improve job performance [14, 15]. People will inevitably have expectations about what the FIR will bring. These expectations will affect current and future performance. Therefore, workers with more positive expectations about the FIR are more likely to create positive outcomes in the present and the FIR eras. Expectancy for the FIR will play an important role in achieving high performance in the current and the FIR eras.

\subsubsection{Acceptance of change}

Acceptance of change by the members of an organization is crucial in order for that orgnization to be able to adapt and succeed in a rapidly changing situation [16]. If people do not adapt to changes that occur in an organization, changes may become failures. Thus, otganizational change strategies must be based on people accepting change. People can have fear or anxiety about change, apprehension about the future, and a desire to maintain the status quo. For these reasons, people may not welcome or accept change and may fail to adapt. On the other hand, workers who are more accepting of change have a higher chance of successfully adapting to it. Thus, people's readiness to accept change is important for change itself to be successful and effective $[17,18]$. Organizations can change more effectively if people's acceptance of change is higher [19]. Thus, psychological factors such as acceptance of change have a positive impact on the success of change. Acceptance of change refers to acknowledging change and striving to adapt to change [16, 17, 19]. The more accepting people are of the changes this transition will bring, the more likely it is that they will be able to adapt more successfully and achieve higher performance.

\subsection{MCs and the relationship between attitudes and performance-related variables}

\subsubsection{Big data and the relationship between attitudes and performance- related variables}

Big data essentiallly refers to the ability to process and analyze huge amounts of information, and sometimes come up with revolutionary new conclusions [20]. The most valuable part of Big data is the characteristics of the data. Big data involves a huge amount of data, variety, and data velocity [21]. Today, companies analyze and use Big data in decision making and management. Big data plays a key role in improving corporate performance [22, 23]. The advantages of Big data are clear. Examples of how this new technology affects business include: better-targeted marketing, helping to develop definitions of churn and other customer behaviors, more numerous and accurate business insights, a better understanding of business changes, better planning and forecasting, identification of the root causes of cost, considering the analytic applications for the detection of fraud, finding the quantification of risks, and automate decisions [21]. Big data is one of the key elements of the FIR era and 
will lead us to a changed world and new opportunities. In addition, many companies and people are aware of the importance of Big data, and are using it directly. According to results released in 2014, 93\% of workers were found to know, understand or use Big data [20, 21].

With regard to the FIR, Big data has already been considered an important factor, and there is a consensus that it is a target of use for businesses. Specific attitudes to Big data will have relevance to performance-related factors for the FIR. Those who have the ability to analyze Big data or have the capacity to utilize Big data are more likely to be positive towards overall changes in the FIR age. Thus, specific attitudes to Big data may increase the self-efficacy, expectancy, and acceptance of change for the FIR. The most necessary attitudes toward Big data will be efficacious to use and intention to use. Anyone who can use Big data well will have greater efficacy in the FIR era. The willingness of certain workers to use Big data is premised on the willingness to learn or make use of this technology. These workers are more likely to use Big data analysis. Those with this capability will better accommodate the changes in the FIR age and have higher expectations for this future. Thus, efficacy to use and intention to use Big data will play major roles in increasing self-efficacy, expectancy, and acceptance of change for the FIR. Further, people need to be aware that Big data is important, and that it will have a positive impact on their performance. Workers who are aware of these cognitions agree that Big data is necessary. These workers have a higher probability of learning or using Big data analysis to improve their performance. This will in turn improve the acceptance, expectation, and efficacy of the FIR changes. Thus, importance and belief in improvement will have a positive impact on the performance-related variables for the FIR. Finally, a negative attitude will have a negative impact on changes to the FIR era. There are people who hold the negative view that Big data is hard to manage from a technical viewpoint [21]. However, Big data is one of the most popular business analytics techniques today, and a negative perception of Big data reflects a failure to adapt to innovative technology, which can even hinder a workers' ability to complete their assigned work. Therefore a negative attitude toward Big data could hinder performances in the FIR era. Based on this relevance, the study sets the following hypotheses:

H1. Attitudes to Big data will influence performance-related variables for the FIR

Table 1. Sub-hypotheses

\begin{tabular}{|c|c|c|c|}
\hline & $h 1-1 \sim h 1-5$ & $h 1-6 \sim h 1-10$ & $h 1-11 \sim h 1-15$ \\
\hline Seeing Big data as important will increase & \multirow{5}{*}{$\begin{array}{l}\text { self-efficacy } \\
\text { for the FIR }\end{array}$} & \multirow{5}{*}{$\begin{array}{l}\text { expectancy } \\
\text { for the FIR }\end{array}$} & \multirow{5}{*}{$\begin{array}{l}\text { increase } \\
\text { accept } \\
\text { of change } \\
\text { for the FIR }\end{array}$} \\
\hline Higher intention to use Big data will increase & & & \\
\hline $\begin{array}{l}\text { Higher belief in improvements from Big data will } \\
\text { increase }\end{array}$ & & & \\
\hline Higher efficacy to use Big data will increase & & & \\
\hline Negative cognition about Big data will decrease & & & \\
\hline
\end{tabular}

\subsubsection{Al and the relationship between attitudes and performance-related variables}

AI is intelligence displayed by machines that is different from natural intelligence, which is demonstrated by people or animals. AI is related to machine learning and automatism, and attempts to solve problems in human lives [24, 25]. AI is an intelligent agent that recognizes the environment, maximizes opportunities and solves problems in order to achieve its goals 
[25]. Organizational management activities are aimed at setting goals, sensitively responding to changes in the environment, and achieving performance. Hence, AI can be used to solve problems in various management activities and to achieve a wider range of goals. AI perceives and learns in order to achieve goals and solve problems [26]. The development of AI has had a varying impact on the performance of workers and enterprises. Already, global leaders such as Apple, Amazon, Google, and Samsung are focused on launching AI-based products and acquiring AI-related venture companies. As interest in AI increases, a variety of responses are emerging. Of course, AI has negative aspects, such as replacing human labor and ultimately jobs. However, more and more companies are turning to the variety of new values that can be gained from AI [27]. AI will enable a variety of innovations including cost savings, and widespread changes in work practices. Today, companies are dealing with issues related to AI such as the technologies behind automation, human-machine interfaces, and both replacing and enhancing people. AI will continue to be used to solve problems in conjunction with humans, and to improve corporate performance [24, 28, 29].

AI will have an impact in a vast number of areas, including on business activities in the future, such as during the FIR. AI will play an important role in the FIR era as well as the present, and some attitudes to AI will be related to the FIR related performance variables. In particular, negative views about AI will have a significant impact on workers attitudes. An important and contentious discussion topic stemming from the rise of $\mathrm{AI}$ is that of whether AI will replace or enhance people in the workplace. When machines become smarter than humans, or better at performing certain tasks, some people will become anxious that they may lose their jobs and may come to regard themselves as essentially worthless in the workplace, whereas other people are able to recognize the benefits that AI will bring and strive to adapt to it and use it positively [27, 30]. Negative attitudes will reduce the willingness to use AI and hinder performance improvement through AI. People who have negative attitudes to AI will not use or learn to use it. Although AI will be very valuable in the FIR era, these workers will not be able to achieve performance gains through AI. Thus, a negative attitude to AI will reduce performance-related variables for the FIR. In contrast, positive attitudes to AI will improve performance-related variables for the FIR. Like Big data, AI will play a very crucial role in the FIR era. Companies need to use AI to become more efficient, solve problems, and achieve their goals. Hence, people should recognize the importance of AI, possess the will to use it, and believe that AI will improve performance. These attitudes will make the adoption of AI a more positive experience. Furthermore, those who think that they have the ability to utilize AI will be able to achieve higher results in the FIR era. Based on theses concepts, this study sets the following hypotheses:

H2. Attitudes to AI will influence performance-related variables for the FIR (Subhypotheses are the same as hypotheses 1-1 to 1-15. The difference is that H1 refers to attitudes to Big data, and $\mathrm{H} 2$ refers to attitudes to $\mathrm{AI}$ )

\subsubsection{Cloud Computing and the relationship between attitudes and performance-related variables}

Cloud Computing is a model that allows for on-demand network access that is ubiquitous and easy to deploy on a shared pool of configurable computing resources. It can be quickly provisioned and deployed with minimal administrative effort. The cloud model consists of essential technical characteristics: shared resource pooling, on-demand self-service, large scale network access, high scalability and rapid elasticity and dynamic resource scheduling 
[31, 32, 33]. Cloud Computing brings innovation to the enterprise environment. Small businesses as well as large corporations can leverage this technology. With Cloud Computing, venture companies can lower the barriers to innovation from IT. Cloud Computing can change the organizational size and structures of existing companies [34]. Companies can also use Cloud Computing to reduce management costs, save time, be more responsive, and more clearly solve problems [31].

Experts believe that Cloud Computing will bring about a revolution in the IT industry [31, 34]. This innovative technology will play an important role in the FIR era and will be applied to the business environment [35]. Companies use Cloud Computing to share vast amounts of information, gain creativity, and solve problems [31, 32, 36]. Workers who use Cloud Computing should be able to share, utilize, and apply information for problem solving through this technology. With Cloud compiling, companies should have market-orientation and create new business models [37]. Information sharing and diversity should be used by entrepreneurs to create new value [38]. Hence, the most important attitude towards Cloud Computing will be intention to use. If people are not willing to use Cloud Computing and do not share information, Cloud Computing will not be as effective as it could be. Workers who are willing to create new value while sharing information will be able to achieve better results in the FIR era. Further, as workers become aware of the importance of Cloud Computing, and see this technology as improving their work, the probability of its use will increase. Thus, importance about Cloud Computing and belief in improvement will also have a positive impact on performance-related variables for FIR. In addition, the efficacy of using Cloud Computing will encourage confidence in achieving high performance in the FIR era, and make people more receptive toward to FIR. Finally, if Cloud Computing is perceived negatively, people will not share information or fully utilize resources. Therefore, there will be problems in securing creativity in the current and FIR eras, and overall performance will be reduced. Based on these relationships, the following hypotheses are set:

H3. Attitudes to Cloud Computing will influence performance-related variables for the FIR (Sub-hypotheses are the same as hypotheses 1-1 to 1-15. The difference is that $\mathrm{H} 1$ refers to attitudes to Big data, and H3 refers to attitudes to Cloud Computing)

\subsubsection{IoT and the relationship between attitudes and performance-related variables}

IoT refers to the interconnection of physical objects equipped with actuators, means, and sensors for connecting to the Internet [39]. IoT plans to connect digital and physical objects with appropriate information and communication technologies to enable whole new kinds of applications and services in the future [40]. IoT integrates all of the interactive objects through an embedded system, increasing the ubiquity of the Internet and connecting it to a highly distributed device network that communicates with humans and other devices. Due to the rapid development of basic technology, IoT offers tremendous opportunities for numerous new applications that can improve the quality of life [41]. This technology has been studied to facilitate the development of new applications and enhancement of existing applications in a variety of areas such as business, workplace support, company performance and management $[40,42]$. IoT involves and facilitates innovation, and can be used in a variety of businesses and organizations. IoT can help build innovative business models [43]. IoT applications can become an important source of revenue, which can bring corporate financial benefits in both the present and future [42]. As with other innovative technologies, 
as people prepare for the FIR era, using IoT will improve management efficiency [40, 43, 44]. Existing IoT technologies still face several problems and challenges, such as mechanical performance and cost constraints, scalability, data transfer and management, heterogenous networks, standardization, and practical applications in various industries [45]. The most important element of IoT in relation to the solution of these problems is the ability to use it well in the work context. In the FIR era, workers should be able to fully understand these complex and new technologies, and complement and exploit their weaknesses. Therefore, efficacy to use to IoT will be most closely related to performance-related variables. Further, intent to use, which is related to the ability using IoT will play a key role. Cognitions that IoT is negative will have a detrimental impact on performance by reducing the willingness to learn or use it. In addition, belief in improvement and importance will be positively related directly or indirectly with performance-related variables, because they are concepts that are opposed to negative attitudes. Depending on these concepts, the following hypotheses are set:

H4. Attitudes to IoT will influence performance-related variables for the FIR (Subhypotheses are the same as hypotheses 1-1 to 1-15. The difference is that $H 1$ refers to attitudes to Big data, and Hs 4 refers to attitudes to IoT)

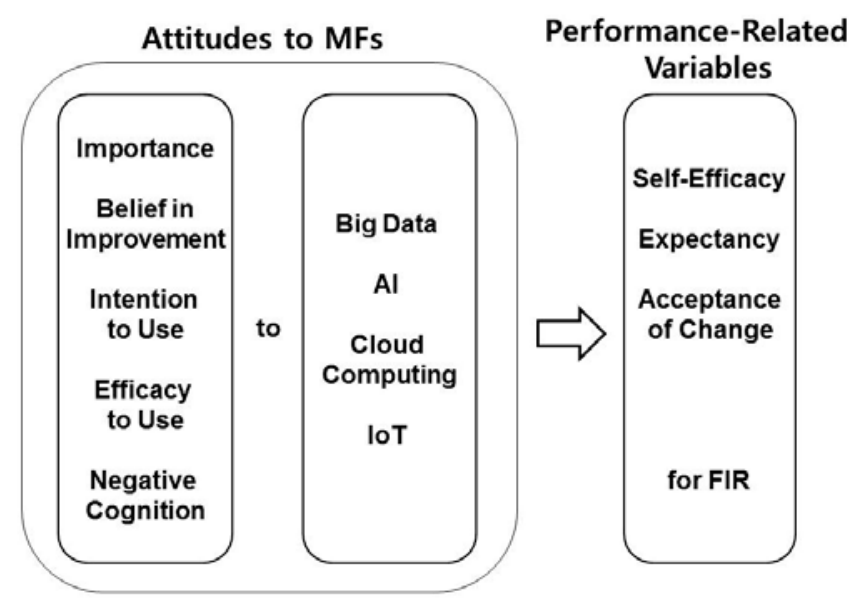

Fig. 1. Research Model

\section{Participants and Measurement}

\subsection{Participants}

Data were collected from 191 workers in the IT industry. Demographic information on these people is as follows: 140 (73.3\%) of the workers were male, and 51 (26.7 \%) were female; $34(17.8 \%)$ were in their twenties, 64 (33.5\%) were thirties, 65 (34\%) were forties, and 28 (14.7\%) were fifty or over; 10 (5.2\%) had completed high school, 149 (78\%) held a bachelor degree, $32(16.8 \%)$ held a masters or doctoral degree; 14 people $(4.3 \%)$ had worked for less than 1 year, 62 (32.5,\%) had worked for from 1 to 5 years, 59 (30.9\%) had worked from 5 to 10 years, 56 (29.3\%) had worked for longer than 10 years at their companies. 


\subsection{Measurement}

All items were rated on a Likert-type scale ranging (1:totally disagree, 7:totally agree). Selfefficacy for the FIR was measured by 5 items [7, 9, 12], including "I feel confident about my ability to perform well at my job in the FIR era", "I feel that I will be on top of things concerning my job in the FIR era". Expectancy for the FIR was measured by 11 items [10, 14], including "I will get more compensation and higher bonuses in FIR era", I will find more job opportunities in the FIR era”. Accept of change for the FIR was measured by 6 items [16, 17], including "I have become more enthusiastic since moving to the FIR era", "In regards to the FIR era, I think it depends on whether individuals gain some advantage or not.

In addition, each attitude to MCs (importance, intention to use, belief in improvement, efficacy to use, negative cognition) was measured by 3 items (see Appendix).

\section{Analysis}

For the empirical analysis of this research, confirmatory factor analysis (CFA), Cronbach's $\alpha$ for reliability, descriptive statistics, liner regression are used [46]. Factor analysis is a statistical approach for identifying and understanding unobservable variables presumed to underlie a set of connected measurements [47]. In presenting statistics, all variables are abbreviated as follows in Table 2

Table 2. Abbreviations of variables

\begin{tabular}{|c|c|c|c|c|}
\hline & Big data & AI & Cloud Computing & IoT \\
\hline Importance about & I_BIG & I_AI & I_CC & I_IT \\
\hline Intention to use about & U_BIG & U_AI & U_CC & U_IT \\
\hline Belief in improvement about & B_BIG & B_AI & B_CC & B_IT \\
\hline Efficacy to use about & E_BIG & E_AI & E_CC & E_IT \\
\hline Negative cognition about & N_BIG & N_AI & N_CC & N_IT \\
\hline E_FIR: self-efficacy for FIR, EX_FIR: expectancy for FIR, AC_FIR: acceptance of change for FIR \\
\hline
\end{tabular}

CFA are suggested in Table 3. As performance-related variables, self-efficacy for the FIR [7, 9, 12], expectancy for the FIR [10, 14] and acceptance of change for the FIR [16, 17] have already proven validity in existing researches. However, the five attitudes to MCs were operationally defined and measured in this paper. Thus, to confirm the validity of these measurements, CFA of these attitudes was conducted separately. As a result, attitude variables and performance-related variables have an acceptable level of validity.

Table 3. Results of CFA

\begin{tabular}{|c|c|c|c|c|c|c|c|c|}
\hline Factor & AVE & CR & Factor & AVE & $\mathrm{CR}$ & Factor & AVE & CR \\
\hline I_BIG & .661 & .772 & I_CC & .719 & .836 & \multirow{4}{*}{ EX_FIR } & \multirow{4}{*}{.639} & \multirow{4}{*}{.930} \\
\hline U_BIG & .747 & .845 & U_CC & .710 & .830 & & & \\
\hline B_BIG & .670 & .792 & B_CC & .694 & .846 & & & \\
\hline E_BIG & .645 & .763 & E_CC & .660 & .808 & & & \\
\hline N_BIGN & .695 & .743 & N_CC & .784 & .816 & SE_FIR & .715 & .909 \\
\hline
\end{tabular}




\begin{tabular}{|c|c|c|c|c|c|c|c|c|}
\hline I_AI & .686 & .801 & I_IT & .719 & .806 & & & \\
\hline U_AI & .671 & .800 & U_IT & .628 & .766 & & & \\
\hline B_AI & .684 & .814 & B_IT & .714 & .811 & & & \\
\hline E_AI & .685 & .790 & E_IT & .664 & .783 & \multirow{2}{*}{ AC_FIR } & \multirow{2}{*}{.611} & \multirow{2}{*}{.877} \\
\hline N_AI & .727 & .761 & N_IT & .793 & .831 & & & \\
\hline \multirow{3}{*}{$\begin{array}{l}\text { Absolute fit } \\
\text { index }\end{array}$} & \multicolumn{2}{|c|}{$X^{2}(p)$} & \multicolumn{3}{|c|}{2638.641} & $X^{2}(p)$ & \multicolumn{2}{|c|}{375.151} \\
\hline & \multicolumn{2}{|c|}{$X^{2} / d f$} & \multicolumn{3}{|c|}{1.783} & $X^{2} / d f$ & \multicolumn{2}{|c|}{1.830} \\
\hline & \multicolumn{2}{|c|}{ RMSEA } & \multicolumn{3}{|c|}{.064} & RMSEA & \multicolumn{2}{|c|}{.066} \\
\hline \multirow{2}{*}{$\begin{array}{l}\text { Incremental fit } \\
\text { index }\end{array}$} & \multicolumn{2}{|c|}{ CFI } & \multicolumn{3}{|c|}{.900} & CFI & \multicolumn{2}{|c|}{.952} \\
\hline & \multicolumn{2}{|c|}{ IFI } & \multicolumn{3}{|c|}{.903} & IFI & \multicolumn{2}{|c|}{.953} \\
\hline \multirow{2}{*}{$\begin{array}{l}\text { Parsimonious } \\
\text { fit index }\end{array}$} & \multicolumn{2}{|c|}{ PNFI } & \multicolumn{3}{|c|}{.671} & PNFI & \multicolumn{2}{|c|}{.800} \\
\hline & \multicolumn{2}{|c|}{ PGFI } & \multicolumn{3}{|c|}{.560} & PGFI & \multicolumn{2}{|c|}{.685} \\
\hline
\end{tabular}

Table 4 indicates the results of descriptive statistics (mean and standard deviation) and the results of reliability. It demonstrates that they have acceptable values (when Cronbach's $\alpha$ is higher than .8) [48].

Table 4. Results of reliability and descriptive statistics

\begin{tabular}{|c|c|c|c|c|c|c|c|}
\hline Variables & Cronbach's $\boldsymbol{\alpha}$ & Mean & $\begin{array}{c}\text { Std. } \\
\text { Deviation }\end{array}$ & Variables & Cronbach's $\boldsymbol{\alpha}$ & Mean & $\begin{array}{c}\text { Std. } \\
\text { Deviation }\end{array}$ \\
\hline \hline I_BIG & .855 & 4.887 & 1.168 & U_CC & .885 & 5.084 & 1.113 \\
\hline U_BIG & .897 & 5.189 & 1.165 & B_CC & .872 & 4.937 & 0.997 \\
\hline B_BIG & .871 & 5.066 & 1.135 & E_CC & .846 & 4.927 & 1.029 \\
\hline E_BIG & .834 & 4.756 & 1.130 & N_CC & .913 & 3.196 & 1.444 \\
\hline N_BIG & .867 & 3.271 & 1.353 & I_IT & .881 & 4.827 & 1.222 \\
\hline I_AI & .868 & 4.876 & 1.136 & U_IT & .845 & 4.960 & 1.101 \\
\hline U_AI & .854 & 5.040 & 1.093 & B_IT & .885 & 4.784 & 1.192 \\
\hline B_AI & .866 & 4.941 & 1.087 & E_IT & .854 & 4.756 & 1.125 \\
\hline E_AI & .863 & 4.693 & 1.180 & N_IT & .916 & 3.269 & 1.426 \\
\hline N_AI & .884 & 3.463 & 1.431 & SE_FIR & .826 & 4.976 & 0.989 \\
\hline I_CC & .884 & 4.937 & 1.107 & EX_FIR & .950 & 4.768 & 0.991 \\
\hline & & & & AC_FIR & .899 & 4.896 & 0.927 \\
\hline
\end{tabular}

Table 5 presents the results of the correlation analysis between attitudes to MCs and performance-related variables. All attitudes to MCs were significantly correlated with every performance-related variable [46]. This result implies that all the hypotheses set forth above are supported 
Table 5. Results of correlation between attitudes to MCs and performance-related variables

\begin{tabular}{|c|c|c|c|}
\hline & $\begin{array}{c}\text { self efficacy } \\
\text { for FIR }\end{array}$ & $\begin{array}{c}\text { Expectancy } \\
\text { for FIR }\end{array}$ & $\begin{array}{c}\text { acceptance of } \\
\text { change for FIR }\end{array}$ \\
\hline Importance about Big data & $.495^{* * *}$ & $.488^{* * *}$ & $.407^{* * *}$ \\
Intention to use about Big data & $.453^{* * *}$ & $.447^{* * *}$ & $.404^{* * *}$ \\
\hline Belief in improvement about Big data & $.525^{* * *}$ & $.540^{* * *}$ & $.458^{* * *}$ \\
Efficacy to use about Big data & $.557^{* * *}$ & $.515^{* * *}$ & $.467^{* * *}$ \\
\hline Negative cognition about Big data & $-.218^{* *}$ & $-.164^{*}$ & $-.198^{* *}$ \\
\hline Importance about AI & $.534^{* * *}$ & $.539^{* * *}$ & $.521^{* * *}$ \\
\hline Intention to use about AI & $.503^{* * *}$ & $.509^{* * *}$ & $.507^{* * *}$ \\
\hline Belief in improvement about AI & $.572^{* * *}$ & $.576^{* * *}$ & $.531^{* * *}$ \\
\hline Efficacy to use about AI & $.566^{* * *}$ & $.488^{* * *}$ & $.487^{* * *}$ \\
\hline Negative cognition about AI & $-.266^{* * *}$ & $-.247^{* * *}$ & $-.291^{* * *}$ \\
\hline Importance about Cloud Computing & $.520^{* * *}$ & $.523^{* * *}$ & $.430^{* * *}$ \\
\hline Intention to use about Cloud Computing & $.468^{* * *}$ & $.468^{* * *}$ & $.447^{* * *}$ \\
\hline Belief in improvement about Cloud Computing & $.496^{* * *}$ & $.531^{* * *}$ & $.448^{* * *}$ \\
\hline Efficacy to use about Cloud Computing & $.527^{* * *}$ & $.502^{* * *}$ & $.491^{* * *}$ \\
\hline Negative cognition about Cloud Computing & $-.263^{* * *}$ & $-.197^{* * *}$ & $-.261^{* * *}$ \\
\hline Importance about IoT & $.599^{* * *}$ & $.636^{* * *}$ & $.560^{* * *}$ \\
\hline Intention to use about IoT & $.550^{* * *}$ & $.598^{* * *}$ & $.522^{* * *}$ \\
\hline Belief in improvement about IoT & $.603^{* * *}$ & $.632^{* * *}$ & $.505^{* * *}$ \\
\hline Efficacy to use about IoT & $.673^{* * *}$ & $.653^{* * *}$ & $.621^{* * *}$ \\
\hline Negative cognition about IoT & $-.208^{* *}$ & $-.177^{*}$ & $-.233^{* *}$ \\
\hline
\end{tabular}

$\star \star \star ~=p<.001,{ }^{\star \star}=p<.01,{ }^{*}=p<0.5$

Table 6 indicates the results of the linear regression, which shows the effects of attitudes to Big data on performance-related variables. The results show that efficacy to use about Big data increases self-efficacy for the FIR $(\beta=.447$, sig=.000), expectancy for the FIR $(\beta=.274$, sig=.009), and acceptance of change for the FIR $(\beta=.375$, sig=.001). In contrast, negative cognition about Big data decreases self-efficacy for the FIR $(\beta=-.179$, sig=.008), and acceptance of change for the FIR ( $\beta=-.152$, sig=.035). Further, belief in improvement can enhance expectancy for the FIR $(\beta=.299$, sig=.022). 
Table 6. The effects of attitudes to Big data on performance-related variables

\begin{tabular}{|c|c|c|c|c|c|c|c|c|c|}
\hline & \multicolumn{3}{|c|}{ SE_FIR } & \multicolumn{3}{|c|}{ EX_FIR } & \multicolumn{3}{|c|}{ AC_FIR } \\
\hline & $\beta$ & $t$ & sig & $\beta$ & $t$ & sig & $\beta$ & $t$ & sig \\
\hline I_BIG & .030 & .260 & .796 & .058 & .489 & .625 & -.061 & -.495 & .621 \\
\hline U_BIG & -.013 & -.111 & .912 & -.039 & -.326 & .745 & .055 & .445 & .657 \\
\hline B_BIG & .130 & 1.030 & .304 & .299 & 2.309 & .022 & .141 & 1.041 & .299 \\
\hline E_BIG & .447 & 4.448 & .000 & .274 & 2.647 & .009 & .375 & 3.472 & .001 \\
\hline N_BIGN & -.179 & -2.681 & .008 & -.081 & -1.181 & .239 & -.152 & -2.119 & .035 \\
\hline$R^{2}$ (Adjusted $R^{2}$ ) & \multicolumn{3}{|c|}{$.365(.348)$} & \multicolumn{3}{|c|}{.327 (.309) } & \multicolumn{3}{|c|}{$.267(.247)$} \\
\hline$F$ & \multicolumn{3}{|c|}{21.277 (sig=.000) } & \multicolumn{3}{|c|}{$17.966(\mathrm{sig}=.000)$} & \multicolumn{3}{|c|}{13.486 (sig=.000) } \\
\hline
\end{tabular}

Table 7 displays the effects of attitudes to AI on performance-related variables. The results show that, efficacy to use about AI increases self-efficacy for the FIR $(\beta=.308$, sig=.001), and acceptance of change for the FIR $(\beta=.187$, sig=.056). In contrast, negative cognition about AI decreases self-efficacy for the FIR ( $\beta=-.130$, sig=.042), and acceptance of change for the FIR $(\beta=-.145$, sig=.028). Moreover, belief in improvement enhances expectancy for the FIR $(\beta=.337$, sig=.010).

Table 7. The effects of attitudes to AI on performance-related variables

\begin{tabular}{|c|c|c|c|c|c|c|c|c|c|}
\hline & \multicolumn{3}{|c|}{ SE_FIR } & \multicolumn{3}{|c|}{ EX_FIR } & \multicolumn{3}{|c|}{ AC_FIR } \\
\hline & $\beta$ & $t$ & sig & $\beta$ & $t$ & sig & $\beta$ & $t$ & sig \\
\hline I_AI & .112 & .974 & .331 & .188 & 1.591 & .113 & .169 & 1.410 & .160 \\
\hline U_AI & .006 & .055 & .957 & -.012 & -.101 & .920 & .079 & .636 & .526 \\
\hline B_AI & .203 & 1.622 & .107 & .337 & 2.620 & .010 & .146 & 1.121 & .264 \\
\hline E_AI & .308 & 3.298 & .001 & .092 & .965 & .336 & .187. & 1.920 & .056 \\
\hline N_AI & -.130 & -2.047 & .042 & -.091 & -1.396 & .164 & -.145 & -2.209 & .028 \\
\hline$R^{2}$ (Adjusted $R^{2}$ ) & \multicolumn{3}{|c|}{$.388(.372)$} & \multicolumn{3}{|c|}{.357 (.339) } & \multicolumn{3}{|c|}{$.339(.321)$} \\
\hline$F$ & \multicolumn{3}{|c|}{23.498 (sig=.000) } & \multicolumn{3}{|c|}{20.507 (sig=.000) } & \multicolumn{3}{|c|}{$18.945(\mathrm{sig}=.000)$} \\
\hline
\end{tabular}

Table 8 shows the effects of attitudes to Cloud Computing on performance-related variables. The results show that efficacy to use about Cloud Computing enhances selfefficacy for the FIR $(\beta=.322$, sig=.001), expectancy for the FIR $(\beta=.188$, sig=.062), and acceptance of change for the FIR $(\beta=.364$, sig=.001). In contrast, negative cognition about Cloud Computing decreases self-efficacy for the FIR $(\beta=-.132$, sig=.052), and acceptance of change for the FIR $(\beta=-.142$, sig=.044). In addition, belief in improvement increases expectancy for the FIR $(\beta=.262$, sig=.025). 
Table 8. The effects of attitudes to Cloud Computing on performance-related variables

\begin{tabular}{|c|c|c|c|c|c|c|c|c|c|}
\hline & \multicolumn{3}{|c|}{ SE_FIR_FIR } & \multicolumn{3}{c|}{ EX_FIR } & \multicolumn{3}{c|}{ AC_FIR } \\
\cline { 2 - 11 } & $\beta$ & $t$ & sig & $\beta$ & $t$ & sig & $\beta$ & $t$ & sig \\
\hline I_CC & .243 & 1.879 & .062 & .251 & 1.927 & .056 & -.037 & -.274 & .785 \\
\hline U_CC & -.105 & -.809 & .419 & -.105 & -.801 & .424 & .096 & .711 & .478 \\
\hline B_CC & .102 & .885 & .377 & .262 & 2.258 & .025 & .082 & .684 & .495 \\
\hline E_CC & .322 & 3.239 & .001 & .188 & 1.875 & .062 & .364 & 3.528 & .001 \\
\hline N_CC & -.132 & -1.956 & .052 & -.034 & -.504 & .615 & -.142 & -2.033 & .044 \\
\hline$R^{2}\left(\right.$ Adjusted $\left.R^{2}\right)$ & \multicolumn{3}{|c|}{$332(.314)$} & \multicolumn{3}{c|}{$.322(.304)$} & & $.279(.260)$ \\
\hline$F$ & $18.403(\mathrm{sig}=.000)$ & \multicolumn{3}{c|}{$17.591(\mathrm{sig}=.000)$} & $148.349(\mathrm{sig}=.000)$ \\
\hline
\end{tabular}

Table 9 indicates the results of the effects of attitudes to IoT on performance-related variables. The results show that efficacy to use about IoT increases self-efficacy for the FIR $(\beta=.511)$, sig=.000), expectancy for the FIR $(\beta=.322$, sig=.001), and acceptance of change for the FIR $(\beta=.517$, sig=.000). In contrast, negative cognition about IoT decreases acceptance of change for the FIR $(\beta=-.102$, sig=.099). Furthermore, belief in improvement increases expectancy for the FIR $(\beta=.184$, sig=.093).

Table 9. The effects of attitudes to IoT on performance-related variables

\begin{tabular}{|c|c|c|c|c|c|c|c|c|c|}
\hline & \multicolumn{9}{c|}{ Dependant } \\
\hline & \multicolumn{3}{|c|}{ SE_FIR } & \multicolumn{3}{c|}{ EX_FIR } & \multicolumn{3}{c|}{ AC_FIR } \\
\cline { 2 - 11 } & $\beta$ & $t$ & sig & $\beta$ & $t$ & sig & $\beta$ & $t$ & sig \\
\hline I_IT & .140 & 1.246 & .214 & .206 & 1.822 & .070 & .212 & 1.777 & .077 \\
\hline U_IT & -.123 & -1.100 & .273 & .024 & .213 & .831 & -.025 & -.216 & .830 \\
\hline B_IT & .162 & 1.491 & .138 & .184 & 1.689 & .093 & -.082 & -.709 & .479 \\
\hline E_IT & .511 & 5.191 & .000 & .322 & 3.267 & .001 & .517 & 4.957 & .000 \\
\hline N_IT & -.082 & -1.421 & .157 & -.015 & -.266 & .790 & -.102 & -1.660 & .099 \\
\hline$R^{2}$ (Adjusted $\left.R^{2}\right)$ & \multicolumn{3}{|c|}{$.475(.461)$} & \multicolumn{3}{c|}{$.474(.460)$} & \multicolumn{3}{c|}{$.409(.393)$} \\
\hline$F$ & $33.515(\mathrm{sig}=.000)$ & \multicolumn{3}{c|}{$33.374(\mathrm{sig}=.000)$} & $25.637(\mathrm{sig}=.000)$ \\
\hline
\end{tabular}

\section{Conclusion}

\subsection{Results and Implications}

This study assumes the need for self-efficacy, expectancy, and acceptance of change for the FIR era. To improve these performance-related factors, it describes the necessary attitudes for the key elements of the FIR era - MCs (Big data, AI, cloud computing, and IoT). According to the results of the statistical analysis, all attitudes to MCs and performancerelated variables have significant relationships. In particular, efficacy to use, negative cognition, and belief in improvement have proven to be important (see Table 10). 
Table 10. The crucial effects of attitudes to MCs on performance-related variables

\begin{tabular}{|c|c|c|c|c|}
\hline \multirow{2}{*}{ MCs } & \multirow{2}{*}{ Attitudes } & \multicolumn{3}{|c|}{ Performance-related variables } \\
\hline & & SE_FIR & EX_FIR & AC_FIR \\
\hline \multirow{3}{*}{ Big data } & Efficacy to use & 0 & 0 & 0 \\
\hline & Negative cognition & 0 & - & 0 \\
\hline & Belief in improvement & - & ○ & - \\
\hline \multirow{3}{*}{ AI } & Efficacy to use & $\circ$ & - & $\Delta$ \\
\hline & Negative cognition & ○ & - & $\circ$ \\
\hline & Belief in improvement & - & o & \\
\hline \multirow{3}{*}{$\begin{array}{c}\text { Cloud } \\
\text { computing }\end{array}$} & Efficacy to use & ○ & $\Delta$ & 0 \\
\hline & Negative cognition & $\Delta$ & - & 0 \\
\hline & Belief in improvement & - & 0 & - \\
\hline \multirow{3}{*}{ IoT } & Efficacy to use & ○ & 0 & O- \\
\hline & Negative cognition & - & - & $\Delta$ \\
\hline & Belief in improvement & - & $\Delta$ & - \\
\hline
\end{tabular}

$\circ$ : strongly influenced, $\Delta$ : influenced, - : related

The implications that can be drawn from these results are as follows:

First, this study highlights the importance of self-efficacy, expectancy, and acceptance of change for the FIR era. If workers' performance-related variables are high, they will produce better results in the near future, coinciding with the arrival of the FIR. As such, efforts should be made to improve these variables. Performance can vary depending on the attitudes adopted byworkers $[11,38]$. Workers should possess the attitudes highlighted in this study to have the best chance of successfully preparing for the FIR. Companies should also hire employees with these attitudes and support existing workers to develop them. For example, a future-oriented leader can increase the expectation of a member, and the successful experience of a worker can enhance self-efficacy [6, 14].

Second, this paper explains the basic attitudes we should have about the core elements of the FIR era, such as Big data, AI, cloud computing, and IoT. For these MCs, workers should have specific attitudes such as importance, belief in improvement, intention to use, and efficacy to use, and not have negative cognition. People should be positive about the FIR and MCs. Workers with a positive attitude to the FIR and MCs will be more confident about the transition to the FIR era and will be more valuable in that era. It is also necessary for enterprises to provide education so that workers can develop and reinforce positive attitudes to MCs. For instance, corporate leaders can leverage the evidence from Big data in major decision making. Also workers can learn the skills of IoT and utilize this technology in all of their tasks. This way, they will be better able to adapt and achieve results in the FIR era.

Third, according to the results of the analysis, efficacy to use plays a major role when compared to other attitudes; and for each of the MCs, it has a large impact on most performance-related variables. Hence, it is important that workers possess self-efficacy for MCs. Thus, firstly workers should strive to increase self-efficacy. This can be done by developing their ability to make good use of MCs, and the greater a worker's competency 
and skill with MCs the more their self efficacy will increase. Secondly, successful experiences using MCs have a key impact on improving self-efficacy [6]. If people have a positive experience using MCs to improve performance or solve problems, their self-efficacy will also improve. Therefore, workers should try to apply MCs to their work. In addition, self-efficacy reflects an individual's expectation and belief in oneself [6, 7]. Thus, an individual worker should have confidence in one's ability and expect to be able to use MCs to achieve high performance. Further, leaders will have to exert influence to increase the self-efficacy of workers. For instance, transformational leadership improves workers' selfefficacy $[8,49]$. Thus, specific leadership can help workers to increase their self-efficacy so that companies can better prepare for a successful future.

Fourth, negative cognition to MCs generally inhibited self-efficacy and acceptance of change for the FIR. Thus, we should try not to have negative cognition to the FIR and MCs. If workers have a negative perception of the FIR and MCs, they will have difficulty adapting to the FIR era. Thus firms should be able to identify the causes of workers' negative attitudes to MCs. Further, companies should provide opportunities to have diverse experiences of these technologies so that workers' negative attitudes can be changed to positive attitudes. Through such support, workers will come to understand the merits of MCs, and consider MCs' worthy of exploitation. This positive attitude will have positive results in the FIR era.

Fifth, belief in improvement has been found to improve expectancy for the FIR. We should believe that MCs will improve business performance now and in the future. If people have this belief, they will have a positive attitude to MCs and also use MCs more frequently. Workers will come to have a belief in improvement by looking at their co-workers or supervisors' successful experiences of MCs as well as their own experience improving work performance with MCs [6, 12]. Thus, colleagues can become a successful example or a leader can be a role model so that members of the organization will have a definite belief in improvement. Through such belief, workers' performance-related variables for the FIR era will increase, and they will be able to achieve the required performance levels in the FIR.

\subsection{Limitations and Potential Areas of Future Study}

First, sepcific psychological states or attitudes of workers can improve the performance of IT organizations which are directly related to FIR [38]. This study assumes that self-efficacy, expectancy, and acceptance of change for the FIR are performance-related variables. As such, we need to study whether these variables are actually related to organization's performance. Future studies should investigate whether a high level of these variables improves performance, and if this is the case further studies should emphasize the importance of these variables.

Second, psychological factors will also be important in improving performance in the FIR era. The development of MCs and various technologies should be directed so as to support and satisfy human beings [50]. Therefore, in addition to the attitudes suggested in this study, future researchs need to be undertaken on the influence of various psychological factors and ways sought to improve performance.

Third, MCs can be used in a wide variety of applications by companies using mobiles. This capability will ultimately influence the success of the firm [51]. Hence, we need to know what kind of support should be provided so that workers can use MCs better.

Finally, in order to measure attitudes, this study made operational definitions, and a questionnaire with 3 items for each variable was conducted. In future studies, more precise attitude measurement tools should be developed. Further, the survey still had the limitations 
of statistical problems such as the adoption of the self-reporting method. Lastly, we used data collected solely from IT industry workers, primarily as their line of work can be seen as being closely related to the FIR era. Future studies should be conducted on workers in other industries.

\section{References}

[1] Klaus Schwab, The Fourth Industrial Revolution, Crown Business, 2017.

[2] Mihyun Chung and Jaehyun Kim, "The internet information and technology research directions based on the fourth industrial revolution," KSII Transactions on Internet \& Information Systems, vol. 10, no. 3, pp. 1311-1320, March, 2016. Article (CrossRef Link)

[3] Keliang Zhou, Taigang Liu and Lifeng Zhou, "Industry 4.0: Towards future industrial opportunities and challenges," in Proc. of Fuzzy Systems and Knowledge Discovery (FSKD), 2015 12th International Conference on. IEEE, pp. 2147-2152, August, 2015. Article (CrossRef Link)

[4] Jay Lee, HungAn Kao and Shanhu Yang, "Service innovation and smart analytics for industry 4.0 and big data environment,” Procedia Cirp 16, pp. 3-8, December, 2014. Article (CrossRef Link)

[5] Genther Schuh, Till Potente, Cathrin Wesch-Potente, Anja Ruth Weber and Jan-Philipp Prote, "Collaboration mechanisms to increase productivity in the context of industrie 4.0," Procedia CIRP 19, pp. 51-56, December, 2014. Article (CrossRef Link)

[6] Albert Bandura, "Self-efficacy,” V. S. Ramachaudran (Ed.), Encyclopedia of Human Behavior, vol. 4, pp. 71-81, New York: Academic Press, 1994.

[7] Robert W. Renn and Donald B. Fedor, "Development and field test of a feedback seeking, selfefficacy, and goal setting model of work performance," Journal of Management, vol. 27, no. 5, pp. 563-583, September-October, 2001. Article (CrossRef Link)

[8] Cameron M. Ford, "A theory of individual creative action in multiple social domains," Academy of Management Review, vol. 21, no. 4, pp. 1112-1142, October, 1996. Article (CrossRef Link)

[9] Albert Bandura, "Self-efficacy: Toward a unifying theory of behavioral change," Psychological Review, vol. 84, no. 2, pp. 191-215, April, 1977. Article (CrossRef Link)

[10] James M. Olson, Neal J. Roese and Mark P. Zanna, "Expectancies," in E. T. Higgins and A, W. Kruglanski (Ed.), Social Psychology: Handbook of Basic Principles, pp. 211-238, New York: Guilford Press, 1996.

[11] Victor H. Vroom, "Work and Motivation,” John Wiley \& Sons, 1964.

[12] Albert Bandura, "Social Learning Theory," Prentice-Hall, Englewood Cliffos, New Jersey, 1977.

[13] John W. Atkinson, "Toward experimental analysis of human motivation in terms of motives, expectancies, and incentives," J. W. Atkinson (Ed.), Motives in Fantasy, Action, and Society, pp. 288-305, Princeton: Van Nostrand, 1958.

[14] E. E. Lawler III and J. L. Suttle, "Expectancy theory and job behavior," Organizational Behavior and Human Performance, vol. 9, no. 3, pp. 482-503, June, 1973. Article (CrossRef Link)

[15] Allan Wigfield and Jacquelynne S. Eccles, "Expectancy-value theory of achievement motivation," Contemporary Educational Psychology, vol. 25, no. 1, pp. 68-81, February, 2000. Article (CrossRef Link)

[16] Marie H. Kavanagh and Neal M. Ashkanasy, "The impact of leadership and change management strategy on organizational culture and individual acceptance of change during a merger," British Journal of Management, vol. 17, no. S1, pp. S81-S103, March, 2006. Article (CrossRef Link)

[17] Marylene Gagne, Richard Koestner and Miron Zuckerman, "Facilitating acceptance of organizational change: The importance of self determination," Journal of Applied Social Psychology, vol. 30, no. 9, pp. 1843-1852, September, 2000. Article (CrossRef Link)

[18] Abraham Sagie and Meni Ed Koslowsky, "Decision type, organisational control, and acceptance of change: An integrative approach to participative decision making," Applied Psychology: An International Review, vol. 45, no. 1, pp. 85-92, January, 1996. Article (CrossRef Link) 
[19] Abraham Sagie, Dov Elizur and Meni Koslowsky, "Effect of participation in strategic and tactical decisions on acceptance of planned change,” The Journal of Social Psychology, vol. 130, no. 4, pp. 459-465, August, 1990. Article (CrossRef Link)

[20] John Walker Saint, "Big data: A revolution that will transform how we live, work, and think," International Journal of Advertising, vol. 33, no. 1, pp. 181-183, January, 2014. Article (CrossRef Link)

[21] Phlip Russom, "Big data analytics,” TDWI Best Practices Report, Fourth Quarter, vol. 19, no. 4, pp. 1-34, 2011.

[22] Ki Youn Kim, "Business intelligence and marketing insights in an era of Big Data: The Q-sorting approach,” KSII Transactions on Internet \& Information Systems, vol. 8, no. 2, pp. 567-582, February, 2014. Article (CrossRef Link)

[23] Joon Park and Seung Ryul Jeong, "A study on the relative importance of underlying competencies of business analysts,” KSII Transactions on Internet \& Information Systems, vol. 10, no. 8, pp. 3986-4007, August, 2016. Article (CrossRef Link)

[24] Don Norman, "Design, Business Models, and Human-Technology Teamwork: As automation and artificial intelligence technologies develop, we need to think less about human-machine interfaces and more about human-machine teamwork," Research Technology Management, vol. 60, no. 1, pp. 26-30, January, 2017. Article (CrossRef Link)

[25] David Poole, Alan Mackworth and Randy Goebel, "Computational Intelligence: A Logical Approach,” Oxford University Press, New York, 1998.

[26] Stuart J. Russell and Peter Norvig, “Artificial Intelligence: A Modern Approach (3rd ed.)," Prentice Hall, Upper Saddle River, New Jersey, 2009.

[27] Ajay Agrawal, Joshua S. Gans and Avi Goldfarb, "What to expect from artificial intelligence," MIT Sloan Management Review, vol. 58, no. 3, pp. 23-27, Spring, 2017.Article (CrossRef Link)

[28] Efraim Turban, Jay E. Aronson and Ting-Peng Liang, "Decision Support Systems and Intelligent Systems,” Yogyakarta: Penerbit Andi, $7^{\text {th }}$ edition, 2005.

[29] Erik Brynjolfsson and Andrew Mcafee, “The business of artificial intelligence," Harvard Business Review, 2017.

[30] Nick Bostrom, "Strategic implications of openness in AI development," Global Policy, vol. 8, no. 2, pp. 135-148, February, 2017. Article (CrossRef Link)

[31] Michael Armbrust, Armando Fox, Rean Griffith, Anthony D. Joseph, Randy Katz, Andy Konwinski, Gunho Lee, David Patterson, Ariel Rabkin, Ion Stoica and Matei Zaharia, “A view of cloud computing,” Communications of the ACM, vol. 53, no. 4, pp. 50-58, April, 2010. Article (CrossRef Link)

[32] Peter Mell and Timothy Grance, “The NIST definition of cloud computing," Special Publication 800-145, pp. 1-3, September, 2011. Article (CrossRef Link)

[33] Ling Qian, Zhiguo Luo, Yujian Du, and Leitao Guo, “Cloud computing: An overview,” in Proc. of IEEE International Conference on Cloud Computing, pp. 626-631, December 1-4, 2009.

[34] Sean Marston, Zhi Li, Subhajyoti Bandyopadhyay, Juheng Zhang and Anand Ghalsasi, "Cloud Computing- The business perspective,” Decision Support Systems, vol. 51, no. 1, pp. 176-189, April, 2011. Article (CrossRef Link)

[35] Hua Xu, Weiqing Liu, Guansheng Shu and Jing Li, "LDBAS: Location-aware data block allocation strategy for hdfs-based applications in the cloud,” KSII Transactions on Internet and Information Systems, vol. 12, no. 1, pp. 204-226, January, 2018. Article (CrossRef Link)

[36] Tharam Dillon, Chen Wu and Elizabeth Chang, "Cloud computing: issues and challenges," in Proc. of 2010 24th IEEE International Conference on Advanced Information Networking and Applications, pp. 27-33, May, 2010. Article (CrossRef Link)

[37] Hoang T. Dinh, Chonho Lee, Dusit Niyato and Ping Wang, “A survey of mobile cloud computing: Architecture, applications, and approaches,” Wireless Communications and Mobile Computing, vol. 13, no. 18, pp. 1587-1611, October, 2011. Article (CrossRef Link) 
[38] Sangwoo Hahm, "Information sharing and creativity in a virtual team: Roles of authentic leadership, sharing team climate and psychological empowerment," KSII Transactions on Internet and Information Systems, vol. 11, no. 8, pp. 4105-4119, August, 2017.

Article (CrossRef Link)

[39] Eva Bucherer and Dieter Uckelmann, "Business models for the internet of things,” Architecting the Internet of Things, pp. 253-277, March, 2011. Article (CrossRef Link)

[40] Daniele Miorandi, Sabrina Sicari, Francesco De Pellegrini and Imrich Chlamtac, "Internet of things: Vision, applications and research challenges,” Ad Hoc Networks, vol. 10, no. 7, pp. 14971516, September, 2012.

[41] Feng Xia, Laurence T. Yang, Lizhe Wang and Alexwy Vinel, “Internet of things,” International Journal of Communication Systems, vol. 25, no. 9, pp. 1101-1102, August, 2012. Article (CrossRef Link)

[42] Remco M. Dijkman, B. Sprenkels, Thijs Peeters and A. Janssen, "Business models for the Internet of Things,” International Journal of Information Management, vol. 35, no. 6, pp. 672678, December, 2015. Article (CrossRef Link)

[43] Elgar Fleisch, Markus Weinberger and Felix Wortmann, "Business models and the internet of things," Interoperability and Open-Source Solutions for the Internet of Things, pp. 6-10, September, 2015.

[44] Meesun Kim, Hyun Ahn and Kwanhoon P. Kim, "Process-aware internet of things: A conceptual extension of the internet of things framework and architecture," KSII Transactions on Internet and Information Systems, vol. 10, no. 8, pp. 4008-4022, August, 2016. Article (CrossRef Link)

[45] $\mathrm{Li} \mathrm{Da} \mathrm{Xu}, \mathrm{Wu} \mathrm{He}$ and Shancang Li, "Internet of things in industries: A survey," IEEE Transactions on Industrial Informatics, vol. 10, no. 4, pp. 2233-2243, November, 2014. Article (CrossRef Link)

[46] Jacob Cohen, "Statistical Power Analysis for the Behavioral Sciences," 2nd Edition, Lawrence Earlbaum Associates, Hilsdale, 1977.

[47] Bruce Thompson, "Exploratory and Confirmatory Factor Analysis: Understanding Concepts and Applications,” American Psychological Association, Washington DC, 2004.

[48] J. Reynaldo A. Santos, “Cronbach’s alpha: A tool for assessing the reliability of scales,” Journal of Extension, vol. 37, no. 2, pp. 1-5, April, 1999.

[49] Swatu Mittal and Rajib Lochan Dhar, "Transformational leadership and employee creativity: mediating role of creative self-efficacy and moderating role of knowledge sharing,” Management Decistion, vol. 53, no. 5, pp. 894-910, 2015. Article (CrossRef Link)

[50] Hyungwoo Park and Sangwoo Hahm, “An interdisciplinary approach to bus information system: bus sensor networking and drivers cognition,” International Journal of Sensor Networks, vol. 24 no 3. pp.183-190, August, 2017. Article (CrossRef Link)

[51] Sangmin Lee, "User behavior of mobile enterprise applications,” KSII Transactions on Internet and Information Systems, vol. 10, no. 8, pp. 3972-3985, August, 2016. Article (CrossRef Link) 
Appendix. Questionares for attitudes to MCs

\begin{tabular}{|l|l|}
\hline \multicolumn{1}{|c|}{ Variable } & \multicolumn{1}{c|}{ Questions } \\
\hline \multirow{4}{*}{ Importance } & I believe MCs is valuable to me. \\
\cline { 2 - 3 } & MCs plays an important role in my work \\
\cline { 2 - 3 } & MCs will become more important in the future \\
\hline \multirow{4}{*}{ Intention to use } & I am willing to use MCs \\
\cline { 2 - 2 } & I will use MCs for my work \\
\cline { 2 - 2 } & MCs will be used more in the future \\
\hline \multirow{4}{*}{ Efficacy to us } & I think MCs is helpful for my job. \\
\cline { 2 - 2 } & MCs will help me improve my performance \\
\cline { 2 - 3 } & $\begin{array}{l}\text { MCs will become more important in the future with regard to } \\
\text { performance improvement }\end{array}$ \\
\hline \multirow{4}{*}{ Negative Cognition } & I have an ability to use MCs \\
\cline { 2 - 2 } & I can use MCs well in my work. \\
\cline { 2 - 2 } & MCs will be more usable in the future \\
\cline { 2 - 2 } & I do not think MCs helps me \\
\cline { 2 - 2 } & MCs will have a negative impact on my work and job. \\
\cline { 2 - 2 } & MCs will make me more vulnerable in the future \\
\hline
\end{tabular}

*MCs are replaced by big data, AI, Cloud Computing and IoT in the questionnaire, respectively.

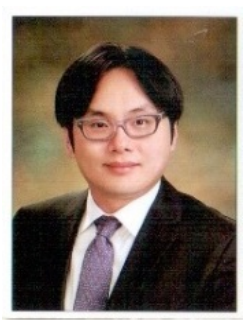

SangWoo Hahm is currently an assistant professor of College of Business Administration at Soongsil, Seoul, Korea. He received his PhD, MS and BS in School of Business Administration from Soonsil University. His current research interests include ebusiness, management, The fourth industrial revolution, organizational behavior, interdisciplinary research and the like. 